\title{
DIGITALLY CONTROLLABLE CURRENT AMPLIFIER AND CURRENT CONVEYORS IN PRACTICAL APPLICATION OF CONTROLLABLE FREQUENCY FILTER
}

\author{
Josef Polak* _ Jan Jerabek* — Lukas Langhammer ${ }^{*}$ \\ Roman Sotner $^{* *}$ _ Jan Dvorak ${ }^{*}$ - David Panek ${ }^{*}$
}

\begin{abstract}
This paper presents the simulations results in comparison with the measured results of the practical realization of the multifunctional second order frequency filter with a Digitally Adjustable Current Amplifier (DACA) and two Dual-Output Controllable Current Conveyors (CCCII $+/-$ ). This filter is designed for use in current mode. The filter was designed of the single input multiple outputs (SIMO) type, therefore it has only one input and three outputs with individual filtering functions. DACA element used in a newly proposed circuit is present in form of an integrated chip and the current conveyors are implemented using the Universal Current Conveyor (UCC) chip with designation UCC-N1B. Proposed frequency filter enables independent control of the pole frequency using parameters of two current conveyors and also independent control of the quality factor by change of a current gain of DACA.

K e y w ords: digitally adjustable current amplifier, current-controlled current conveyor, frequency filter, quality factor, pole frequency, single input multiple outputs
\end{abstract}

\section{INTRODUCTION}

Nowadays, many research teams focus on development of frequency filters with electronically controllable parameters. Many of them operate in current mode because of the possible improvement in signal to noise ratio, increase in dynamic range, in some cases also increasing bandwidth and linearity.

There were presented various proposals of controllable current amplifiers in the open literature. Current amplifiers are basically simple active components that can be easily used in various areas of analogue signal processing. Differential current amplifier (DCA) is introduced in [1] and current differential input amplifier (CDA) including also its full differential version - current differential input differential output amplifier (CDDA) is mentioned in [2]. Some current amplifiers, which are suitable for the current mode, can be found in literature as current operational amplifier (COA) $[3,4]$. Digitally controlled current amplifier (DCCA) can be also included between the current amplifiers. It forms gain stage of variable gain amplifier [5]. VGA consists of three stages. Input stage converts differential input voltage to differential current. Output stage converts differential current into differential output voltage. The middle stage referred as the gain stage (operates with currents) is controlled digitally and thus this circuit is named as Digitally Controlled Current Amplifier (DCCA) [5].
Proposed digitally controlled current amplifier (DACA) is designed to work especially in the current mode. Adjustable current amplifier ACA [7] is similar to DACA, wherein it is possible to control the current gain by the control current in range from $50 \mu \mathrm{A}$ to $280 \mu \mathrm{A}$ (corresponding to output current gain $A$ from 1 to 8 ). The active element ACA, however, was practically never made in form of integrated circuit (IC).

Function principle and control of DACA element current gain is simply mentioned in this article, detailed description of this active element is given in [8]. There are few publications [9-13], dealing with the use of the current amplifier DACA in frequency filters. Some publications deal only with simulations of frequency filters with this active element [9-11].

Alternative circuit implementation of the DACA element is composed from universal voltage conveyors [14], universal current conveyors [15] and EL2082 circuits [16].

Several practical implementations of single-ended (SE) frequency filters and subsequently the fully-differential (FD) frequency filters FD $[12,13]$ with alternative implementation of the DACA were simulated and also practically measured. After verifying the practical functions of the proposed current amplifier, DACA was designed on transistor level and produced in $0.35 \mu \mathrm{m}$ CMOS technology with digital control of current gain designated as DACA_N [17].

\footnotetext{
* Department of Telecommunications, Faculty of Electrical Engineering and Communication, Brno University of Technology, Czech Republic, xpolak24@phd.feec.vutbr.cz; ${ }^{* *}$ Department of Radio Electronics, Faculty of Electrical Engineering and Communication, Brno University of Technology, Czech Republic
} 


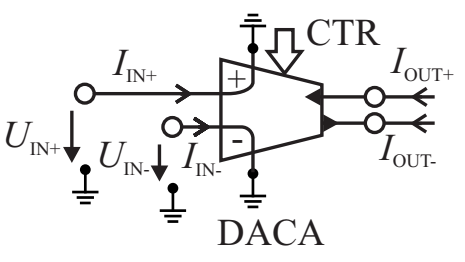

(a)

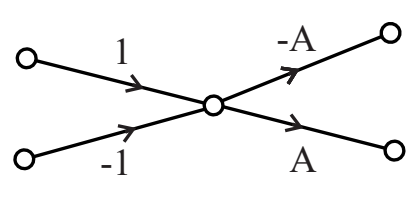

(b)

Fig. 1. Digitally adjustable current amplifier (a) - schematic symbol, (b) - simplified signal-flow graph (SFG) of DACA element

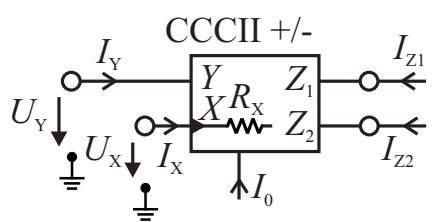

(a)

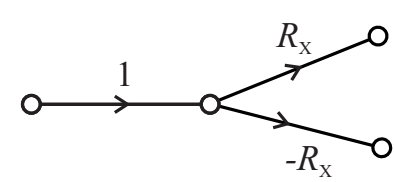

(b)

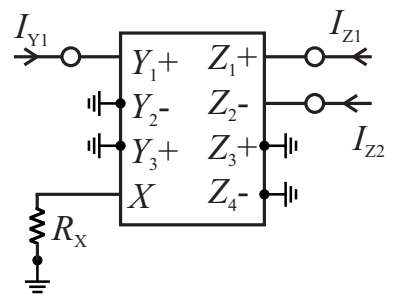

(c)

Fig. 2. Controllable current conveyor of the second generation (a) — schematic symbol, (b) — simplified signal-flow graph (SFG) of CCCII element, (c) — realization using the UCC

In this paper, we present S-E frequency filter with DACA element in form of chip DACA_N. Frequency filter is proposed as a Single Input Multiple Output (SIMO) and allows to obtain these filter functions: low pass (LP), high pass (HP), band stop (BS) and band pass (BP). Another type in the design of frequency filters described in the technical literature are filters of the multiple input multiple output MIMO [18] type, where it is possible to achieve a smaller number of active and passive elements in the availability of all filter functions.

Filter presented in this paper has been designed with respect to the requirement of only one input, and contains only two active elements supplemented by two capacitors and two resistors which enable to control the internal resistance of current conveyors.

\section{DEFINITION OF ACTIVE ELEMENTS}

This part deals with description of active elements which were used in design of our frequency filter. Each active element is presented by schematic symbol, a simplified signal flow graph (SFG) and possible real implementation using a suitable active element (if necessary).

The first used active element is digitally adjustable current amplifier DACA. Controlling of this active element is performed using 3-bit digital bus. The bus con- trols the current gain $\mathrm{A}$ of the active element in the range from 1 to 8 . This active element has two current low impedance inputs and two current high impedance outputs. This active element was made in form of the chip, it is therefore not necessary to implement it by using the equivalent circuit.

More detailed information regarding the use of the simulation model including a comparison of the simulation data with the real values measured on several chips of DACA element are given in [8]. Figure 1 shows a schematic symbol DACA and representation using the SFG method.

Relationships between inputs and outputs are indicated by the following equations

$$
\begin{aligned}
I_{\mathrm{DIF} \_\mathrm{IN}} & =\left(I_{\mathrm{IN}+}-I_{\mathrm{IN}-}\right), \\
I_{\text {DIF_OUT }} & =\left(I_{\mathrm{OUT}+}-I_{\mathrm{OUT}-}\right), \\
I_{\mathrm{OUT}+} & =A\left(I_{\mathrm{IN}+}-I_{\mathrm{IN}-}\right), \\
I_{\mathrm{OUT}-} & =-A\left(I_{\mathrm{IN}+}-I_{\mathrm{IN}-}\right), \\
I_{\text {DIF_OUT }} & =2 A I_{\text {DIF_IN }},
\end{aligned}
$$

where $I_{\text {DIF_IN }}, I_{\text {DIF_OUT }}$ are differential input and output currents respectively.

The second active element used in this frequency filter is current-controlled current conveyor of the second generation (CCCII) practically implemented using a universal conveyor UCC [15], which is in $[19,20]$ referred to as a double output current-controlled current conveyor of the second generation (DO-CCCII). If the CCCII has more than two outputs, it is called the multiple output current-controlled current conveyor of the second generation (MO-CCCII) $[21,22]$. Controlling of this active element is realized using value of resistor $R_{\mathrm{x}}$, which is used to modify the intrinsic resistance of this active element. In the implementation using universal conveyor UCC [15], the active element has a high-impedance input and two high impedance outputs.

Figure 2 shows a schematic symbol, expression using the method of signal flow graphs and implementation using $\mathrm{UCC}$ with the resistor $R_{\mathrm{x}}$, which is used to change the above-mentioned intrinsic resistance of this active element. Relationships between inputs and outputs can be expressed by

$$
I_{\mathrm{Z} 1}=-I_{\mathrm{Z} 2}=I_{\mathrm{X}}=\frac{U_{\mathrm{Y}}-U_{\mathrm{X}}}{R_{\mathrm{X}}} .
$$




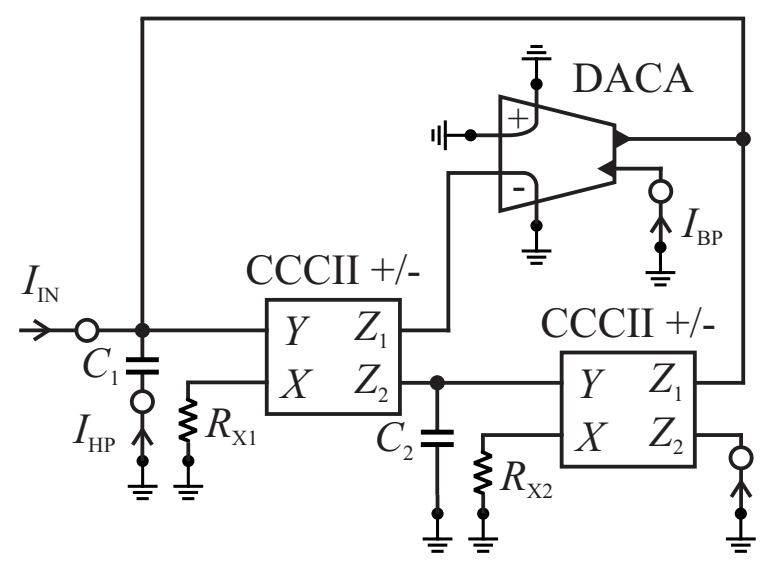

Fig. 3. Scheme of the $2^{\text {nd }}$-order multifunctional frequency filter

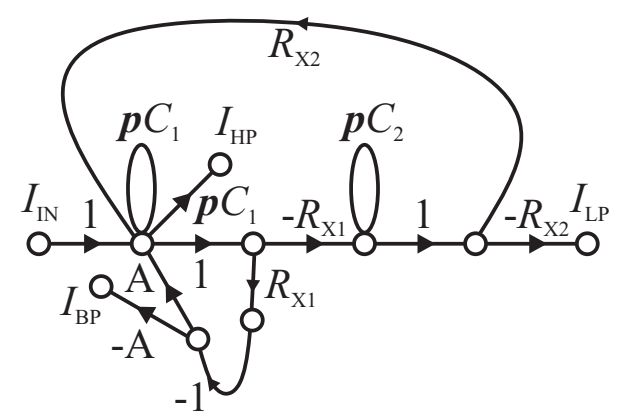

Fig. 4. Simplified signal-flow graph of the $2^{\text {nd }}$-order multifunctional frequency filter

Table 1. Comparison of the pole frequency values of LP response $(A=3)$

\begin{tabular}{cccc}
\hline \multirow{2}{*}{$R_{\mathrm{x} 1,2}(\Omega)$} & \multicolumn{3}{c}{ Pole frequency $(\mathrm{kHz})$} \\
& Theoretical & Simulated & Measured \\
\hline 2400 & 217 & 251 & 229 \\
1200 & 434 & 501 & 461 \\
820 & 634 & 780 & 681 \\
\hline
\end{tabular}

Table 2. Comparison of the quality factor values of the BP response $\left(R_{\mathrm{x} 1,2}=2.4 \mathrm{k} \Omega\right)$

\begin{tabular}{cccccc}
\hline \multicolumn{5}{c}{ Quality factor $Q(-)$} \\
\multicolumn{1}{c}{ Theoretical } & Simulated & Measured \\
\hline A & Q & A & Q & A & Q \\
\hline 1 & 3.3 & 1 & 4.4 & 1 & 3.2 \\
2 & 1.6 & 2 & 2.3 & 2 & 1.6 \\
3 & 1.0 & 3 & 1.4 & 3 & 1.1 \\
4 & 0.8 & 4 & 0.6 & 4 & 0.9 \\
\hline
\end{tabular}

\section{PROPOSAL OF MULTIFUNCTION FREQUENCY FILTER}

Frequency filter presented in this article is proposed using the method of signal flow graphs (SFG). The filter is designed as a multifunctional (HP, LP, BP, BS) secondorder filter with mutually independent control of pole frequency $f_{0}$ and quality factor $Q$. Parameters of two active elements CCCII are used to linearly control the pole frequency - their intrinsic resistance. DACA is an active element, which is used in this proposal to control (with inverse proportion) the quality factor (changing the current gain $A$ of this digitally controlled active element). Figure 3 shows the schematic of that filter and Fig. 4 shows its simplified SFG.

The characteristic equation has form

$$
D(s)=s^{2} C_{1} C_{2}+s C_{2} R_{\mathrm{X} 1} A+R_{\mathrm{X} 1} R_{\mathrm{X} 2},
$$

where $R_{\mathrm{X} 1}, R_{\mathrm{X} 2}$ are intrinsic resistances of CCCII elements and $A$ is current gain of DACA active element. The equations for pole frequency $f_{0}$ and quality factor $Q$ are calculated from equation (7) and are

$$
\begin{aligned}
& f_{0}=\frac{1}{2 \pi} \sqrt{\frac{R_{\mathrm{X} 1} R_{\mathrm{X} 2}}{C_{1} C_{2}}}, \\
& Q=\frac{1}{A} \sqrt{\frac{C_{1} R_{\mathrm{X} 2}}{C_{2} R_{\mathrm{X} 1}}} .
\end{aligned}
$$

Filter functions LP, BP are taken directly from high impedance outputs of active elements. Due to the low number of active elements, HP cannot be taken from high impedance outputs of active elements, filter function HP is taken from the passive element (capacitor $C_{1}$ ) and the same issue applies for BS response. Note that this issue could be easily solved by one additional current follower that is however, not a part of the scheme in Fig. 3. The following equations represent the individual filter functions

$$
\begin{aligned}
& \frac{I_{\mathrm{LP}}}{I_{\mathrm{IN}}}=\frac{R_{\mathrm{X} 1} R_{\mathrm{X} 2}}{D(s)}, \\
& \frac{I_{\mathrm{BP}}}{I_{\mathrm{IN}}}=\frac{s C_{2} R_{\mathrm{X} 1}}{D(s)}, \\
& \frac{I_{\mathrm{HP}}}{I_{\mathrm{IN}}}=\frac{s^{2} C_{1} C_{2}}{D(s)}, \\
& \frac{I_{\mathrm{BS}}}{I_{\mathrm{IN}}}=\frac{s^{2} C_{1} C_{2}+R_{\mathrm{X} 1} R_{\mathrm{X} 2}}{D(s)} .
\end{aligned}
$$

\section{COMPARISON OF SIMULATION AND MEASUREMENT RESULTS}

Correct functionality of the proposed frequency filter was tested in the frequency range from $1 \mathrm{kHz}$ to $20 \mathrm{MHz}$. The simulations were performed in OrCAD with simulation models specified in $[8,23]$. Capacitors values are constant: $C_{1}=780 \mathrm{pF}, C_{2}=120 \mathrm{pF}$. Comparison of pole frequencies of the LP response for the individual values of the control resistors $R_{\mathrm{x} 1}, R_{\mathrm{x} 2}$ in case of theoretical calculations (8), simulations and real measurement are provided in Tab. 1. In this case the value of the current gain $A$ was set to 3 in each case. The exact values of quality factor $Q$ for $A=3$ are shown in Tab. 2 .

Control of the quality factor is performed using a current amplifier DACA, wherein we set the current gain $A$ 


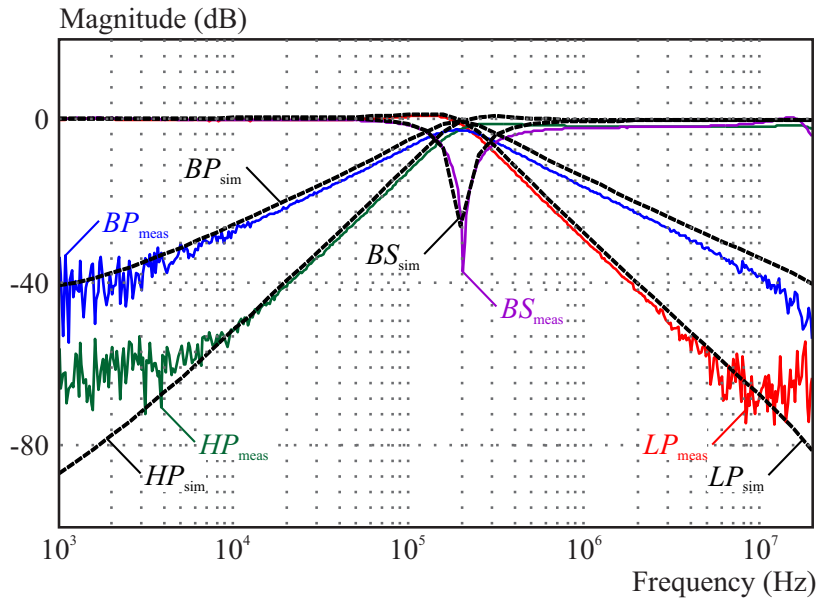

Fig. 5. Comparison of output responses (measurement values with simulated values) of $\mathrm{HP}, \mathrm{LP}, \mathrm{BP}$ and $\mathrm{BS}\left(A=3, R_{x 1,2}=2.4 \mathrm{k} \Omega\right)$

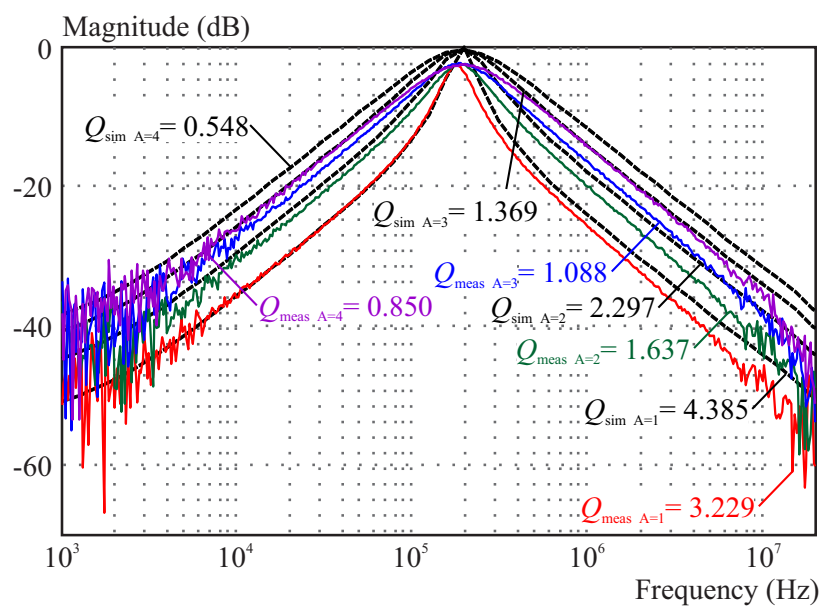

Fig. 7. Demonstration of controlling the quality factor $Q$ of the BP filter $\left(R_{x 1,2}=2.4 \mathrm{k} \Omega\right)$

Table 3. Comparison of the slope of LP, BP, HP $\left(A=3, R_{\mathrm{x} 1,2}=\right.$ $2.4 \mathrm{k} \Omega$ )

\begin{tabular}{cccc}
\hline \multirow{2}{*}{ Filter } & \multicolumn{3}{c}{ Slope $(\mathrm{dB} / \mathrm{dec})$} \\
\cline { 2 - 4 } function & Theoretical & Simulated & Measured \\
\hline LP & 40 & 37.43 & 41.08 \\
HP & 40 & 38.28 & 39.11 \\
BP & 20 & 19.60 & 19.79 \\
\hline
\end{tabular}

Table 4. Comparison of the slope of LP, BP, HP and BS ( $A=3$, $R_{\mathrm{x} 1,2}=2.4 \mathrm{k} \Omega$ )

\begin{tabular}{cccc}
\hline \multirow{2}{*}{$\begin{array}{c}\text { Filter } \\
\text { function }\end{array}$} & \multicolumn{2}{c}{ Phase $\left(^{\circ}\right)$ at frequency $1 \mathrm{kHz}, 1 \mathrm{MHz}$} \\
\cline { 2 - 4 } & Theoretical & Simulated & Measured \\
\hline LP & $0^{\circ},-180^{\circ}$ & $-4^{\circ},-173^{\circ}$ & $3^{\circ},-169^{\circ}$ \\
HP & $180^{\circ}, 0^{\circ}$ & $167^{\circ}, 16^{\circ}$ & $176^{\circ}, 18^{\circ}$ \\
BP & $90^{\circ},-90^{\circ}$ & $77^{\circ},-79^{\circ}$ & $87^{\circ},-76^{\circ}$ \\
BS & $0^{\circ},-360^{\circ}$ & $-4^{\circ},-343^{\circ}$ & $3^{\circ},-228^{\circ}$ \\
\hline
\end{tabular}

on the values indicated in Tab. 2 (for BP response). The-

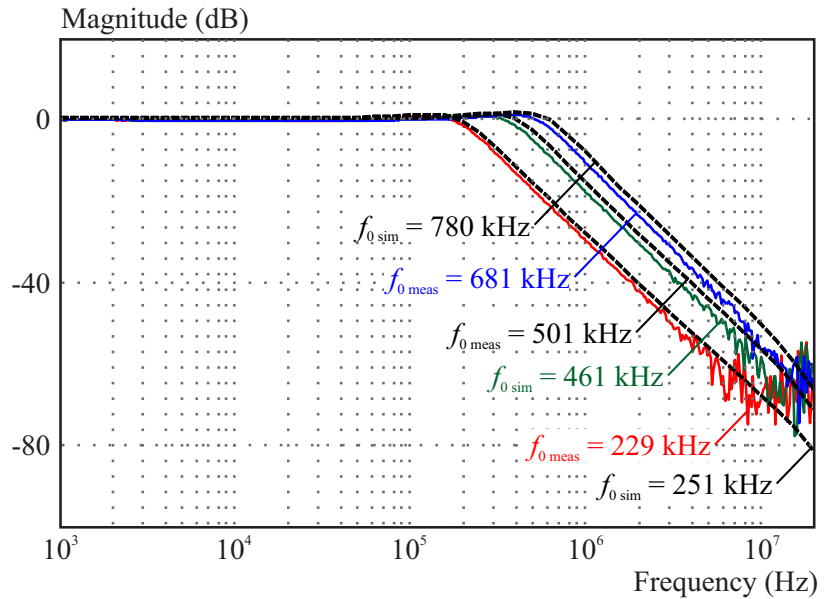

Fig. 6. Demonstration of controlling the pole frequency $f_{0}$ of the LP filter $(A=3)$

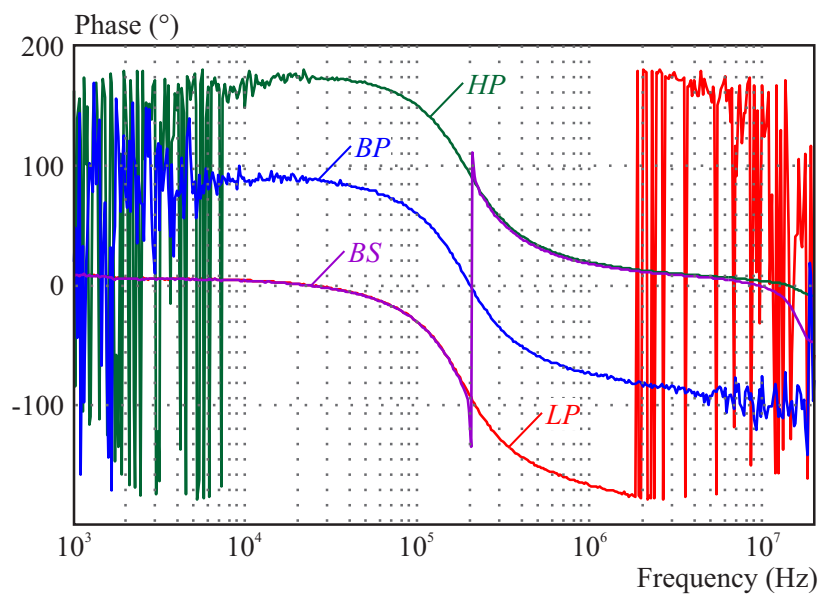

Fig. 8. Phases of HP, LP, BP and BS response $\left(R_{x 1,2}=2.4 \mathrm{k} \Omega\right.$, $A=3$ )

oretical values of $Q$ for individual values of the gain are compared with simulated values and measured values of $Q$. The values of resistors $R_{\mathrm{x} 1}, R_{\mathrm{x} 2}$ were set to $2.4 \mathrm{k} \Omega$ and corresponding values of $f_{0}$ are shown on Tab. 1. A detailed description of the simulation model is presented in [8].

The simulation results and the practical measurement results of individual filter functions of the proposed frequency filter are shown in the following graphs. Graph in Fig. 5 compares the results of the simulations (dashed black curves in all cases ) with measured values (always coloured solid curves) for each of the filter functions. For accuracy, exact values of the slope (for HP, LP, BP) are given in Tab. 3, for this particular scenario: the current gain value was $A=3$ and $R_{\mathrm{x} 1}, R_{\mathrm{x} 2}=2.4 \mathrm{k} \Omega$. The phase values of the individual filter functions at frequencies $10 \mathrm{kHz}$ and $1 \mathrm{MHz}$ are specified In Tab. 4 .

Figure 6 shows a comparison of the measurement and simulation values of the LP response, when the pole frequency $f_{0}$ is controlled by simultaneous change of the values of resistors $R_{\mathrm{x} 1}, R_{\mathrm{x} 2}$. The current gain value of 
DACA element, which enables controlling of $Q^{\prime}$ is set to constant value $A=3$ in this scenario. Comparison of theoretical, simulated and measured values is shown also in Tab. 1. Figure 7 shows the quality factor tuning, in the case of the BP filter with constant values of resistors $R_{\mathrm{x} 1,2}=2.4 \mathrm{k} \Omega$. Particular values (theoretical, simulated and measured) of $Q$ are compared in Tab. 2. The last graph (Fig. 8) shows the individual phases of all functions of the filter. Only measured values for particular values of resistors $R_{\mathrm{x} 1}, R_{\mathrm{x} 2}=2.4 \mathrm{k} \Omega$ are shown, which corresponds to $f_{0}=229 \mathrm{kHz}$. The value of current gain was set to $A=3$, which corresponds to $Q=1.1$. All transfer functions have noninverting character in pass-bands, see Fig. 8 .

Experimental measurement results seem to be better than simulation results as obvious from the graphs. This is given by used simulation models that are prepared in order to represent the worst sample of the DACA current amplifier (worst case simulation model).

\section{CONCLUSION}

This paper presents proposed S-E multifunctional frequency filter of the $2^{\text {nd }}$ order with newly designed and manufactured active element DACA in form of the integrated circuit and two well-known CCCII. Two CCCII are realized by using one UCC-N1B chip, which enables building of the proposed frequency filter with only two integrated circuit packages (DACA, UCC) supplemented by two capacitors and two resistors. In this filter, it is moreover possible to mutually independently control the quality factor and the pole frequency. Presented filter is of the single input multiple outputs (SIMO) type and these outputs (LP, HP, BP, BS) are of positive phase. Simulation results together with the measurement results prove the very good workability of the designed filter.

\section{Acknowledgement}

Research described in this paper was financed by the National Sustainability Program under grant LO1401. For the research, infrastructure of the SIX Center was used.

\section{REFERENCES}

[1] Chrisanthopoulos, A.-SOuliotis, G.-HARITANTIS, I. : Differential Current Amplifiers with Improved Dynamic Range, The $6^{\text {th }}$ IEEE International Conference on Electronics, Circuits and Systems (ICECS 99), Pafos, 1999, pp. 501-504.

[2] SOUliotis, G.-Chrisanthopoulos, A.-HARITANTIS, I. : Current Differential Amplifers: New Circuits and Applications, International Journal of Circuit Theory and Applications (2001), 553-574.

[3] Altun, M.-KUTMAn, H.: Design of a Fully Differential Current Mode Operational Amplifier with Improved Input-Output Impedances and its Filter Applications, International Journal of Electronics and Communications 62 No. 3 (2008), 239-244.
[4] KAulberg, T.: A CMOS Current-Mode Operational Amplifier, IEEE Journal of Solid-State Circuits 6 No. 7 (1993), 849-852.

[5] EL-ADAWY, A. A.-SOlimAN, A. M.-ELWAN, H. O. : Low Voltage Fully Differential CMOS Voltage Mode Digitally Controlled Variable Gain Amplifier, Microelectronics Journal 31 No. 2 (2000), 139-146.

[6] JERABEK, J.-SOTNER, R.-VRBA, K.: Fully-Differential Current Amplifier and its Application to Universal and Adjustable Filter, In 2010 International conference on applied electronics, 2010, pp. 141-144.

[7] HERENCSAR, N.-JERABEK, J.-KOTON, J.-VRBA, K. -MINAEI, S.-GOKNAR, I. C.: Pole Frequency and PassBand Gain Tunable Novel Fully-Differential Current-Mode All-Pass Filter, In Proceedings of the IEEE International Symposium on Circuits and Systems (ISCAS), Lisbon, Portugal, 2015, pp. 2668-2671.

[8] POLAK, J.—LANGHAMMER, L.—JERABEK, J. : Behavioral Modeling of Digitally Adjustable Current Amplifier, International Journal of Advances In Telecommunications, Electrotechnics, Signals and Systems (2015), 1-7, doi: 10.11601/ijates.v4i1.104.

[9] JERABEK, J.-VRBA, K.: Current-Mode Tunable and Adjustable Filter with Digitally Adjustable Current Amplifier and Transconductance Amplifiers, In Proceedings of the European Conference of Circuits Technology and Devices (ECCTD'10), 2010, pp. 101-104.

[10] KOTON, J.-HERENCSAR, N.-VRBA, K.-JERABEK, J. Digitally Adjustable Current Amplifier and its Application in Fully Differential Current-Mode Band-Pass Filter Design, Elektrorevue Internet journal No. 90 (2010), 1-6.

[11] JERABEK, J.-SOTNER, R.-VRBA, K.: Fully-Differential Universal Filter with Current Active Elements, In Proc of the $4^{\text {th }}$ Int. Conf. on Circuits, Systems and Signals (CSS'10), WSEAS, 2010, pp. 83-86.

[12] LANGHAMMER, L.-JERABEK, J.-POLAK, J.: Tunable Fully-Differential Filters Designed Using Signal-Flow Graphs Method, Elektrorevue Internet Journal 6 No. 3 (2015), 38-48.

[13] LANGHAMMER, L.-JERABEK, J.: Fully Differential Universal Current-Mode Frequency Filters Based on Signal-Flow Graphs Method, International Journal of Advances in Telecommunications, Electrotechnics, Signals and Systems 3 No. 1, 1-12.

[14] HERENCSAR, N.-VRBA, K.-KOUDAR, I. : Universal Voltage Conveyor (UVC-N1C 0520), Data Sheet, 2010, http:// www.utko.feec.vutbr.cz/ herencsar/UVC_N1C_0520.pdf.

[15] KOTON, J.-VRBA, K.-KOUDAR, I. : Universal Current Conveyor (UCC) and Second-Generation Current Conveyor (CCII+/-), Data Sheet, 2010, http://

www.utko.feec.vutbr.cz/ koton/soubory/UCC_N1B_Rev0.pdf.

[16] INTERSIL (ELANTEC). EL 2082CN Current-Mode Multiplier, 1996, http://www.intersil.com/data/fn/fn7152.pdf.

[17] JERABEK, J.-VRBA, K.-KOUDAR, I. : Dual Wide-Bandwidth Digitally Adjustable Current Amplifier (DACA), Data Sheet, 2010, http://www.utko.feec.vutbr.cz/ jerabekj/daca.pdf.

[18] TANGSRIRAT, W.: Current-Tunable Current-Mode Multifunction Filter based on Dual-Output Current-Controlled Conveyors, AEU-Int J. Electron. Commun 61 No. 8 (2007), 528-533.

[19] YUCE, E.: Current-Mode Electronically Tunable Biquadratic Filters Consisting of only CCCIIs and Grounded Capacitors, Microelectronics Journal No. 40 (2009), 1719-1725.

[20] ABBAS, Z.-SCOTTI, G.-OLIVIERI, M.: Current Controlled Current Conveyor (CCCII) and Application using $65 \mathrm{~nm}$ CMOS Technology, World Academy of Science, Engineering and Technology 55 (2011), 935-939.

[21] PAUL, S. K.-PANDEY, N.-BHATTACHARYYA, A. : Transadmittance Mode Universal Filter based on MOCCCII, Int. Conf. on Computers and Devices Communication, 2009, $4^{\text {th }}$ Int. Conf. on IEEE, pp. 1-4. 
[22] PANDEY, N.-PAUL, S. K.-JAIN, S. B.: A New Electronically Tunable Current Mode Universal Filter using MO-CCCII, Analog Integrated Circuits and Signal Processing 58 (2009), 171-178, DOI: 10.1007/s10470-008-9232-3.

[23] HERENCSAR, N.-VRBA, K. : Tunable Current-Mode Multifunction Filter using Universal Current Conveyors, Proceedings of the Third International Conference on Systems, Mexico, 2008, pp. 1-6.

Received 11 January 2016

Josef Polák was born in Kutná Hora, Czech Republic, in 1986. He received the MSc degree (2013) from the Brno University of Technology. Currently he is a PhD student at the Faculty of Electrical Engineering and Communication. His interests are analogue circuits (frequency filters, active elements, oscillators, etc), circuits working chiefly in the current mode, simulation and experimental measurement of new proposed analogue circuits.

Jan Jeřábek was born in Bruntál, Czech Republic, in 1982. He received the $\mathrm{PhD}$ degree in Electrical Engineering in 2011 from the Brno University of Technology, Czech Republic. He received MSc and BSc degree from the same university in 2007 and 2005, respectively. He is currently an Assistant Professor at the Department of Telecommunications, Faculty of Electrical Engineering and Communication, Brno University of Technology. His research interests are focused on circuit applications of modern active elements such as current amplifiers and multiple output current followers.
Lukáš Langhammer received the MSc degree in the field of electrical engineering and telecommunication from the Faculty of Electrical Engineering and Communications, Brno University of Technology (BUT), Brno, Czech Republic, in 2012. $\mathrm{He}$ is currently a student of $\mathrm{PhD}$ degree program at the same faculty. He is currently dealing with frequency filters of the fractional order.

Roman Šotner was born in Znojmo, Czech Republic, in 1983. He received the MSc and PhD degrees from the Brno University of Technology, Czech Republic, in 2008 and 2012, respectively. Currently, he is a technical worker at the Department of Radio Electronics, Faculty of Electrical Engineering and Communication, Brno University of Technology, Brno, Czech Republic. His interests are analog circuits (active filters, oscillators, audio, etc), circuits in the current mode, circuits with direct electronic controlling possibilities especially and computer simulation.

Jan Dvořák was born in Boskovice, Czech Republic, in 1990. He received the MSc degree (2015) from the Brno University of Technology. Currently he is a PhD student at the Faculty of Electrical Engineering and Communication. His interests are analog fractional-order circuits and analog frequency filters.

David Panek finished the BSc degree in the field of electrical engineering and telecommunication from the Faculty of Electrical Engineering and Communications, Brno University of Technology (BUT), Brno, Czech Republic, in 2015. 